\title{
Changing individual-level risk factors for malaria with declining transmission in southern Zambia: a cross-sectional study
}

\author{
Catherine G Sutcliffe ${ }^{1}$, Tamaki Kobayashi ${ }^{1}$, Harry Hamapumbu ${ }^{3}$, Timothy Shields ${ }^{2}$, Aniset Kamanga ${ }^{3}$, \\ Sungano Mharakurwa ${ }^{2,3}$, Philip E Thuma ${ }^{3}$, Gregory Glass ${ }^{2}$ and William J Moss ${ }^{1,2^{*}}$
}

\begin{abstract}
Background: Malaria elimination will require that both symptomatic- and asymptomatic-infected persons be identified and treated. However, well-characterized, individual-level risk factors for malaria may not be valid in regions with declining malaria transmission. Changes in individual-level correlates of malaria infection were evaluated over three years in a region of declining malaria transmission in southern Zambia.
\end{abstract}

Methods: Malaria surveys were conducted in two study areas within the catchment area of Macha Hospital, Zambia in 2007 and 2008/2009. A random sample of households was identified from a digitized satellite image of the study areas. Cross-sectional surveys were conducted approximately five times throughout the year in each of the two study areas. During study visits, adults and caretakers of children were administered questionnaires and a blood sample was obtained for a rapid diagnostic test (RDT) for malaria.

Results: In the 2007 study area, 330 individuals were surveyed. 40.9\% of participants lived in a household with at least one insecticide-treated bed net (ITN); however, only 45.2\% reported sleeping under the ITN. 23.9\% of participants were RDT positive. Correlates of RDT positivity included younger age, the presence of symptoms, testing during the rainy season, using an open water source, and not sleeping under an ITN. In the 2008 study area, 435 individuals were surveyed. 77.0\% of participants lived in a household with at least one ITN; however, only 56.4\% reported sleeping under the ITN. $8.1 \%$ of participants were RDT positive. RDT positivity was negatively correlated with the presence of symptoms within the last two weeks but positively correlated with documented fever. In 2009, 716 individuals were surveyed in the same area as 2008. 63.7\% of participants lived in a household with at least one ITN; however, only 57.7\% reported sleeping under the ITN. 1.5\% of participants were RDT positive. Only self-reported fever was significantly correlated with RDT positivity.

Conclusions: With declining malaria prevalence, few individual-level characteristics were correlated with RDT positivity. This lack of correlation with individual characteristics hampers identification of individuals infected with malaria. Strategies based on ecological or environmental risk factors may be needed to target control efforts and achieve further reductions and elimination.

Keywords: malaria, Africa, control strategies, epidemiology

\section{Background}

Globally, 225 million cases of malaria and 781, 000 deaths were estimated to occur in 2009 , with the majority in sub-Saharan Africa [1]. Recent progress in malaria control resulting from the increased availability and

\footnotetext{
* Correspondence: wmoss@jhsph.edu

'Department of Epidemiology, Bloomberg School of Public Health, Johns

Hopkins University, 615 North Wolfe Street, Baltimore, MD, USA

Full list of author information is available at the end of the article
}

coverage of several interventions, including insecticidetreated bed nets (ITNs), effective artemisinin-based combination therapy, indoor residual spraying of households, and intermittent preventive treatment for pregnant women, is thought to have reduced disease burden. Targets have been set by the United Nations, the World Health Assembly and the Roll Back Malaria Partnership to increase coverage of control measures, reduce the number of malaria cases and deaths by $75 \%$ or more by 
2015, and eliminate malaria in several countries [1]. With expanded malaria control programmes, several countries in Africa have documented large and sustained decreases in the burden of disease [1].

In regions that have achieved low levels of transmission, further malaria control and elimination will require that interventions are not only incorporated into national control programmes and accepted and used by individuals, but that symptomatic- and asymptomatic-infected persons be identified and treated. Numerous prior studies identified individual-level risk factors for malaria, but many were conducted in areas of high endemicity [2] and among high-risk groups, such as children [3-5] and pregnant women [6,7]. However, in regions with declining malaria transmission as a result of accelerated control efforts, these well-characterized, individual-level risk factors for malaria may not be valid [8].

Zambia is one of eleven countries in sub-Saharan Africa that achieved a greater than 50\% reduction in the number of malaria cases between 2000 and 2009 [1]. The prevalence of parasitaemia in children younger than five years of age decreased 53\% between the malaria indicator surveys in 2006 and 2008 [9]. Although great spatial heterogeneity remains in the risk of malaria throughout the country, with the highest risk in the northern provinces [10], the Southern Province has witnessed a dramatic decline in the burden of malaria over the past several years [11] and may be a region in which malaria elimination can be achieved [12]. According to a recent Roll Back Malaria Country Report on Zambia, developing an active case-detection system to identify parasites in asymptomatic reservoirs is critical to the development of a malaria elimination programme in Zambia [13]. Such a system requires that communities understand how malaria is transmitted and controlled as well as comply with control programmes, and that highrisk individuals or communities can be identified for targeted interventions. Using a series of cross-sectional studies, the level of general knowledge about malaria, ownership and use of ITNs, and changes in individuallevel correlates of malaria parasitaemia were determined over three years in a region of declining malaria transmission in Southern Province, Zambia.

\section{Methods}

Study site

The study was conducted in the catchment area of Macha Hospital in Choma District, Southern Province, Zambia between April 2007 and December 2009. Macha Hospital is located approximately $70 \mathrm{~km}$ from the nearest town of Choma on a plateau at an altitude of approximately $1,100 \mathrm{~m}$ above sea level and in a habitat characterized as Miombo woodland. There is a single rainy season, lasting from approximately November through April, followed by a cool, dry season from April to August, and a hot, dry season from August to November. The catchment area is populated by traditional villagers living in small, scattered homesteads. Anopheles arabiensis is the primary vector responsible for malaria transmission [14], which peaks during the rainy season. The study site in 2007 consisted of a 525 $\mathrm{km}^{2}$ region to the east of Macha Hospital and the Malaria Institute at Macha (MIAM; Figure 1). In 2008 and 2009, the study site was shifted for logistical reasons to a $575 \mathrm{~km}^{2}$ area west of the 2007 study site and including the hospital.

The Southern Province of Zambia historically had hyperendemic transmission of Plasmodium falciparum [15]. More recently, the entomological inoculation rate (EIR) for An. arabiensis was estimated to range from 1.6 to 18.3 infective bites per person per season [14]. Zambia introduced artemether-lumefantrine as anti-malarial therapy in 2002 and ITNs were widely distributed in Southern Province, Zambia in 2007. Widespread indoor residual spraying was not formally conducted in the study area.

\section{Study methods}

Satellite images were used to construct a sampling frame from which households were selected for enrollment into prospective longitudinal and cross-sectional surveys of malaria parasitaemia. A Quickbird ${ }^{\mathrm{TM}}$ satellite image was obtained from DigitalGlobe Services, Inc. (Denver, Colorado) and imported into ArcGIS 9.2 (Redlands, $\mathrm{CA})$. Structures of appropriate size and shape were identified as potential residences and locations of households were identified and enumerated manually. Simple random sampling was used to select households for the surveys, which were carried out throughout the year.

Study procedures began with community mobilization activities, including approvals from local chiefs and headmen. A field team was provided with images and coordinates of the randomly selected households. Households consisted of one or more domestic structures where members of a family resided. All individuals within a household were eligible to participate. After obtaining permission from the head of household and individual written informed consent, a questionnaire was administered to each participant older than 18 years of age residing within the household and to parents or guardians of those younger than 18 years of age. Data collected included demographic information, history of recent malaria and anti-malarial treatment, knowledge of malaria transmission and prevention, and the use of ITNs. Each participant's temperature was measured using a Braun Thermoscan ${ }^{\circledR}$ ear thermometer. A blood sample was collected by finger prick for a rapid diagnostic test (RDT) for malaria and haemoglobin 


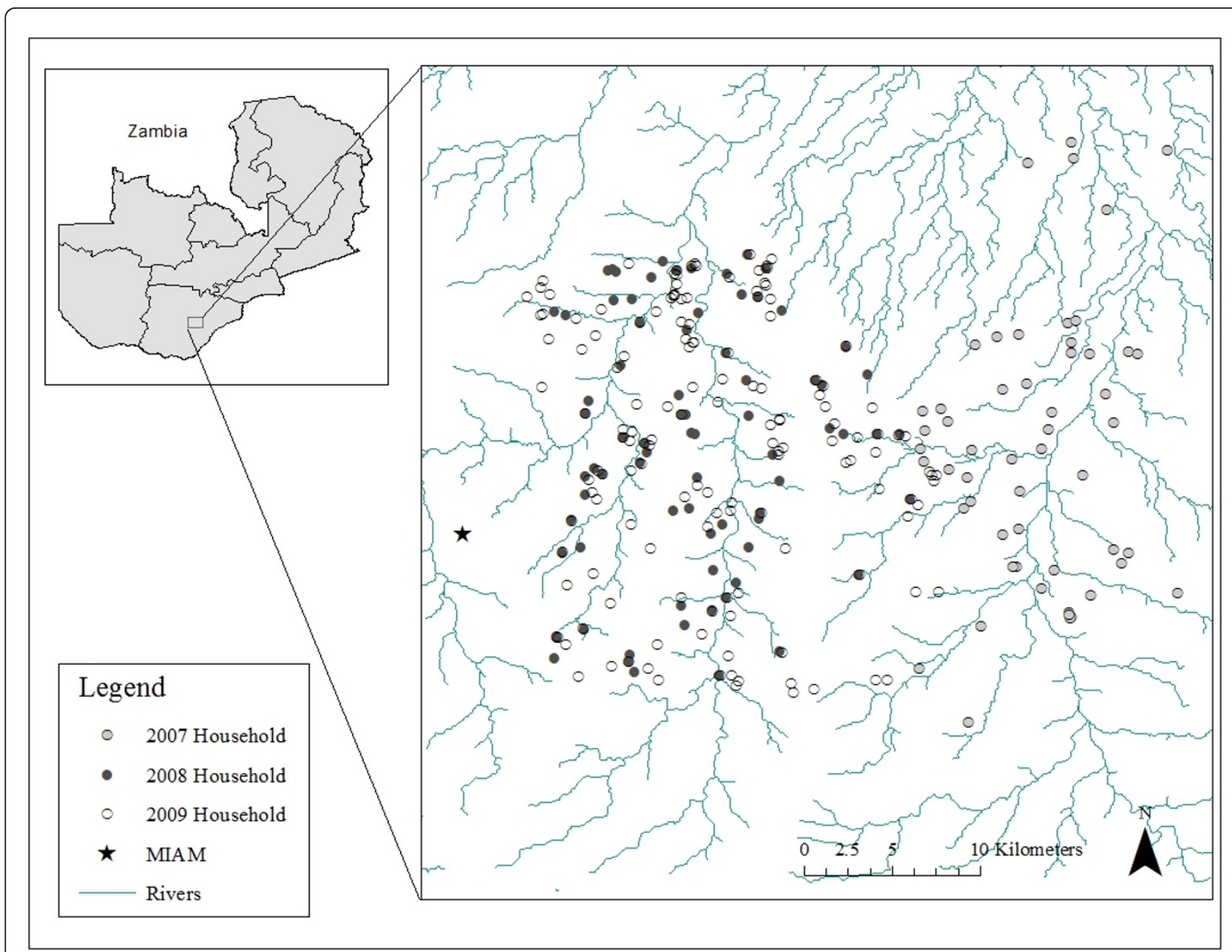

Figure 1 Map of study sites in Southern Province, Zambia. Note: The study site in 2007 consisted of a $525 \mathrm{~km}^{2}$ region to the east of Macha Hospital. In 2008 and 2009, the study site was a $575 \mathrm{~km}^{2}$ area west of the 2007 study site and including the hospital and Malaria Institute at Macha.

determination using a Hemocue ${ }^{\circledR}$ photometer. The RDT (ICT Diagnostics, Cape Town, South Africa) was used to detect $P$. falciparum histidine-rich protein 2 . This RDT was shown to detect $82 \%$ of test samples with wild-type $P$. falciparum at a concentration of 200 parasites $/ \mu \mathrm{L}$ and $98 \%$ of test samples with a concentration of 2, 000 parasites $/ \mu \mathrm{L}$, with false positives in $0.6 \%$ of negative samples [16]. Individuals who were RDT positive were offered treatment with artemether-lumefantrine $\left(\right.$ Coartem $\left.{ }^{\circledR}\right)$.

This study was approved by the University of Zambia Research Ethics Committee and by the Institutional Review Board at the Johns Hopkins Bloomberg School of Public Health.

\section{Statistical methods}

All participants in the cross-sectional surveys and the first visit for participants in the longitudinal cohort were included in this analysis. The rainy season was assumed to occur from January 1 to June 30 and November 1 to December 31, and was defined based on rainfall and hospitalization data from Macha Hospital during the study period. Fever was defined as a temperature greater or equal to $38^{\circ} \mathrm{C}$. Anaemia was defined by age and sex according to World Health Organization criteria [17]. Individuals were considered anaemic if their haemoglobin was $<11 \mathrm{~g} / \mathrm{dL}$ and they were $0-4.9$ years of age; < $11.5 \mathrm{~g} / \mathrm{dL}$ and $5-11.9$ years of age; $<12 \mathrm{~g} / \mathrm{dL}$ and $12-$ 14.9 years of age; $<12 \mathrm{~g} / \mathrm{dL}$, female and $\geq 15$ years of age; $<13 \mathrm{~g} / \mathrm{dL}$, male and $\geq 15$ years of age.

Characteristics hypothesized to be associated with malaria were compared between individuals who were RDT positive and negative using the chi-square test for binary characteristics and the Wilcoxon ranksum test for continuous characteristics. For years in which multiple correlates of RDT positivity were found, crude and 
adjusted prevalence ratios were calculated using logbinomial regression with generalized estimating equations to account for clustering by households. Characteristics that were found to be correlated with RDT positivity in the crude analysis $(\mathrm{p}<0.10)$ were included in the adjusted model.

\section{Results}

\section{Study participants}

In 2007, 72 heads of household were approached to participate and 52 (72\%) agreed to enroll their households. All of the 330 individuals within the households who were approached agreed to participate. In 2008, 81 heads of household were approached to participate and 76 (94\%) agreed to enroll their households. Of the 466 individuals within households who were approached, 435 (93\%) agreed to participate. In 2009, 122 heads of household were approached to participate and 119 (98\%) agreed to enroll their households. Of the 730 individuals within the households who were approached, 716 (98\%) agreed to participate. In all years, the majority of participants were young children and adolescents, and approximately half were male (Table 1 ). The majority of adults had at least primary school education (Table 1). Households were basic, with the majority using public wells or pumps, pit latrines or no toilet facilities, and lanterns. Most structures were built with earth floors, fired brick or cement walls, and pole and grass roofs (Table 1).

\section{General knowledge of malaria}

The majority of adults ( $\geq 18$ years) were familiar with the symptoms, causes and prevention of malaria (Table 2). However, a small proportion of participants reported causes of malaria other than mosquito bites related to eating and drinking. In addition, while most participants knew that sleeping under a bed net prevented malaria, few participants were familiar with other personal preventive measures. In the 2007 study area, a quarter of participants reported they did not know the causes of malaria or prevention measures. Fewer reported not knowing causes or prevention measures in the 2008 and 2009 study area.

The majority of adults reported learning about malaria from health workers $(53.1 \%$ in $2007 ; 53.9 \%$ in 2008 ; $64.0 \%$ in 2009). Others learned from posters in health centres $(13.1 \%$ in $2007 ; 8.2 \%$ in $2008 ; 2.0 \%$ in 2009$)$ and schools $(14.6 \%$ in $2007 ; 18.1 \%$ in $2008 ; 13.8 \%$ in 2009$)$. Less common sources of information included non-governmental organizations, friends, the radio, and the study team. Some participants reported never having learned about malaria $(23.9 \%$ in $2007 ; 11.5 \%$ in $2008 ; 12.5 \%$ in 2009). These participants were more likely to be older and to have less than a primary school education.

\section{ITN use and indoor residual spraying}

Less than half of participants in 2007, but the majority of participants in 2008 and 2009, lived in a household with a bed net (Table 3). Most households only had one bed net. The primary reason for not owning a bed net in all three years was cost. Among participants who owned a bed net, only half slept under the bed net. The primary reason for not sleeping under the bed net was that no mosquitoes were around. The proportion of participants sleeping under a bed net was higher among participants surveyed during the rainy season (2007: 68.2\%; 2008: 65.6\%; 2009: 61.4\%). Other common reasons for not sleeping under the bed net included an inability to hang the bed net or sleeping outside, the bed net was old, dirty or needed to be re-treated, and it was too hot under the bed net. Among those sleeping under the bed net, the majority of participants had owned the net for less than two years and few reported ever having treated the bed net. Upon inspection of the households where participants reported sleeping under bed nets, almost all had the bed nets hanging $(96.7 \%$ in $2007 ; 100 \%$ in 2008 ; $99.6 \%$ in 2009$)$. However, up to half had holes $(49.2 \%$ in 2007 ; $11.6 \%$ in 2008 ; $33.1 \%$ in 2009). The most common brand of bed net used was long-lasting PermaNet ${ }^{\circledR}$ bed nets $(63.9 \%$ in 2007 ; $97.4 \%$ in 2008 ; $99.3 \%$ in 2009 ).

Only $1.8 \%$ of participants in 2007, 1.4\% in 2008 and $2.0 \% 2009$ reported that their house had ever been sprayed with insecticide to control mosquitoes.

\section{Prevalence of malaria, reported symptoms, and correlates of RDT positivity}

The prevalence and correlates of RDT positivity differed by study location and year. In the 2007 study area, 79 (23.9\%) participants were positive for malaria by RDT (Figure 2). RDT positive individuals were significantly more likely to report any symptoms of malaria in the prior 48 hours, including fever, headache, chills, diarrhoea, nausea/vomiting, and cough, and to report multiple symptoms (see Additional file 1). 51.9\% of RDT positive individuals reported a fever in the prior 48 hours, although only $10.1 \%$ had a fever as measured on the day of the study visit. The majority of fevers were documented among infected individuals 5-10 years of age. RDT positivity was also significantly correlated with younger age, not sleeping under a bed net, having a study visit in the rainy season, and using an open water source (see Additional file 1). RDT positivity was marginally positively correlated with the presence of anaemia. Symptoms of malaria, younger age, and using an open water source remained significantly independently correlated with RDT positivity after adjustment for other factors (Table 4). Not sleeping under a bed net and having a study visit in the rainy season were marginally independently correlated with RDT positivity. 
Table 1 Characteristics of the study population and households, by study year

\begin{tabular}{|c|c|c|c|}
\hline & 2007 & 2008 & 2009 \\
\hline Participants & $N=330$ & $N=435$ & $N=716$ \\
\hline Age: Median (IQR) & $12.8(5.2,31.8)$ & $14.3(6.4,34.3)$ & $13.9(6.4,31.5)$ \\
\hline $0-5$ & $76(23.0)$ & $84(19.4)$ & $142(19.8)$ \\
\hline $5-10$ & $67(20.3)$ & $76(17.6)$ & $124(17.3)$ \\
\hline $10-20$ & $63(19.1)$ & $113(26.1)$ & $187(26.1)$ \\
\hline $20-30$ & $37(11.2)$ & $36(8.3)$ & $74(10.3)$ \\
\hline $30-40$ & $34(10.3)$ & $35(8.1)$ & $63(8.8)$ \\
\hline $40-50$ & $23(7.0)$ & $38(8.8)$ & $50(7.0)$ \\
\hline $50-60$ & $8(2.4)$ & $25(5.8)$ & $25(2.5)$ \\
\hline$\geq 60$ & $22(6.7)$ & $26(6.0)$ & $51(7.1)$ \\
\hline Male: N (\%) & $153(46.4)$ & $207(47.6)$ & $342(47.8)$ \\
\hline \multicolumn{4}{|l|}{ Education: N (\%) } \\
\hline$<$ Grade 1 & $3(2.3)$ & $7(3.9)$ & $13(4.4)$ \\
\hline Grade 1-6 & $29(22.3)$ & $64(35.2)$ & $82(27.6)$ \\
\hline Grade 7-12 & $97(74.6)$ & $110(60.4)$ & $197(66.3)$ \\
\hline University/certificate/technical training & $1(0.8)$ & $1(0.6)$ & $5(1.7)$ \\
\hline Households & $N=52$ & $N=76$ & $N=119$ \\
\hline \multicolumn{4}{|l|}{ Source of water: N (\%) } \\
\hline Private well or pump & $5(9.6)$ & $1(1.3)$ & $2(1.7)$ \\
\hline Public well or pump & $30(57.7)$ & $39(51.3)$ & $73(61.3)$ \\
\hline Public stand pipe & $0(0.0)$ & $2(2.6)$ & $1(0.8)$ \\
\hline Unprotected well & $3(5.8)$ & $12(15.8)$ & $22(18.5)$ \\
\hline River or stream & $14(26.9)$ & $22(29.0)$ & $21(17.7)$ \\
\hline \multicolumn{4}{|l|}{ Toilet: N (\%) } \\
\hline Pit latrine & $24(46.2)$ & $37(48.7)$ & $98(82.4)$ \\
\hline No facility/bush/field & $27(51.9)$ & $39(51.3)$ & $21(17.6)$ \\
\hline Other & $1(1.9)$ & $0(0.0)$ & $0(0.0)$ \\
\hline \multicolumn{4}{|l|}{ Source of light: N (\%) } \\
\hline Candle & $4(7.7)$ & $3(4.0)$ & $24(20.2)$ \\
\hline Lantern & $45(86.5)$ & $67(88.2)$ & $77(64.7)$ \\
\hline Other & $3(5.8)$ & $6(7.9)$ & $18(15.1)$ \\
\hline \multicolumn{4}{|l|}{ Material of floor: N (\%) } \\
\hline Cement & $18(34.6)$ & $11(14.5)$ & $29(24.4)$ \\
\hline Earth & $34(65.4)$ & $65(85.5)$ & $90(75.6)$ \\
\hline \multicolumn{4}{|l|}{ Material of walls: N (\%) } \\
\hline Fired brick/cement & $44(84.6)$ & $69(90.8)$ & $106(89.1)$ \\
\hline Pole and mud/grass & $1(1.9)$ & $3(4.0)$ & $9(7.5)$ \\
\hline Unfired bricks & $7(13.5)$ & $4(5.3)$ & $4(3.4)$ \\
\hline \multicolumn{4}{|l|}{ Material of roof: $\mathrm{N}(\%)$} \\
\hline Iron sheets/corrugated tin & $12(23.1)$ & $19(25.0)$ & $34(28.6)$ \\
\hline Pole and grass & $36(69.2)$ & $56(73.4)$ & $82(68.9)$ \\
\hline Other & $4(7.7)$ & $1(1.3)$ & $3(2.5)$ \\
\hline
\end{tabular}

${ }^{a}$ among participants 18 years of age or older 
Table 2 General knowledge of malaria symptoms, causes and prevention among participants 18 years or older, by study year

\begin{tabular}{|c|c|c|c|}
\hline & $\begin{array}{c}2007 \\
N=130\end{array}$ & $\begin{array}{c}2008 \\
N=182\end{array}$ & $\begin{array}{c}2009 \\
N=297\end{array}$ \\
\hline Symptoms of malaria & N (\%) & N (\%) & $\mathrm{N}(\%)$ \\
\hline Fever & $71(54.6)$ & $98(53.9)$ & 175 (58.9) \\
\hline Headache & $45(34.6)$ & $101(55.5)$ & $175(58.9)$ \\
\hline Chills & $71(54.6)$ & $114(62.6)$ & $197(66.3)$ \\
\hline Vomiting & 35 (26.9) & $73(40.1)$ & $111(37.4)$ \\
\hline Diarrhoea & $21(16.2)$ & $40(22.0)$ & $78(26.3)$ \\
\hline Body ache/pain & $14(10.8)$ & $18(9.9)$ & $43(14.5)$ \\
\hline Cough & $4(3.1)$ & $27(14.8)$ & $33(11.1)$ \\
\hline Weakness/fatigue & $11(8.5)$ & $38(20.9)$ & $46(15.5)$ \\
\hline Flu-like symptoms & $1(0.8)$ & $7(3.9)$ & $10(3.4)$ \\
\hline Thirsty & $4(3.1)$ & $8(4.4)$ & $16(5.4)$ \\
\hline Loss of appetite & $14(10.8)$ & $10(5.5)$ & $25(8.4)$ \\
\hline Yellow eyes/skin & 24 (18.5) & $19(10.4)$ & $17(5.7)$ \\
\hline Other & $11(8.5)$ & $13(7.1)$ & $10(3.4)$ \\
\hline Do not know & $14(10.8)$ & $3(1.7)$ & $0(0.0)$ \\
\hline \multicolumn{4}{|l|}{ Causes of malaria } \\
\hline Mosquito bites & $92(70.8)$ & $152(83.5)$ & $258(86.9)$ \\
\hline Breathing bad air & $0(0.0)$ & $0(0.0)$ & $0(0.0)$ \\
\hline Eating bad food & $8(6.2)$ & $8(4.4)$ & $16(5.4)$ \\
\hline Eating fresh maize & $0(0.0)$ & $6(3.3)$ & $19(6.4)$ \\
\hline Eating fresh fruits & $3(2.3)$ & $10(5.5)$ & $16(5.4)$ \\
\hline Eating sugar cane & $0(0.0)$ & $5(2.8)$ & $14(4.7)$ \\
\hline Drinking bad water & $13(10.0)$ & $18(9.9)$ & $50(16.8)$ \\
\hline Dirty surroundings & $2(1.5)$ & $12(6.6)$ & $25(8.4)$ \\
\hline Flies & $0(0.0)$ & $0(0.0)$ & $2(0.7)$ \\
\hline Other & $2(1.5)$ & $3(1.7)$ & $7(2.4)$ \\
\hline Do not know & $33(25.4)$ & $24(13.2)$ & $21(7.1)$ \\
\hline \multicolumn{4}{|l|}{ Preventive measures against malaria } \\
\hline Burn a fire in the house & $1(0.8)$ & $0(0.0)$ & $0(0.0)$ \\
\hline Charms & $4(3.1)$ & $0(0.0)$ & $0(0.0)$ \\
\hline $\begin{array}{l}\text { Do not go outside at certain } \\
\text { times of day }\end{array}$ & $0(0.0)$ & $0(0.0)$ & $0(0.0)$ \\
\hline Have screens on the windows & $0(0.0)$ & $0(0.0)$ & $0(0.0)$ \\
\hline Keep skin covered & $1(0.8)$ & $0(0.0)$ & $1(0.3)$ \\
\hline Sleep under a mosquito net & $52(40.0)$ & $120(65.9)$ & $227(76.4)$ \\
\hline Spray insecticide inside the house & $3(2.3)$ & $7(3.9)$ & $5(1.7)$ \\
\hline Take medicine to prevent malaria & $8(6.2)$ & $16(8.8)$ & $31(10.4)$ \\
\hline Wear insect repellent & $0(0.0)$ & $2(1.1)$ & $3(1.0)$ \\
\hline $\begin{array}{l}\text { Drinking and eating clean water } \\
\text { and food }\end{array}$ & $7(5.4)$ & $12(6.6)$ & $31(10.4)$ \\
\hline Bury mosquito breeding sites & $13(10.0)$ & $20(11.0)$ & $20(6.7)$ \\
\hline Keep surroundings clean & $11(8.5)$ & $49(26.9)$ & $74(24.9)$ \\
\hline Seek early treatment & $8(6.2)$ & $20(11.0)$ & $39(13.1)$ \\
\hline Other & $3(2.3)$ & $5(2.8)$ & $11(3.7)$ \\
\hline Do not know & $55(42.3)$ & $30(16.5)$ & $22(7.4)$ \\
\hline
\end{tabular}

In the 2008 study area, 35 (8.1\%) participants were positive for malaria by RDT (Figure 2). Unexpectedly, RDT positive individuals were less likely to report symptoms of malaria, particularly in the prior two weeks (see Additional file 1). However, RDT positive individuals were significantly more likely to have a fever as measured on the day of the study visit. The majority of fevers were documented among infected individuals 10-15 years of age. No other characteristics correlated with RDT positivity.

In 2009, 11 (1.5\%) participants were positive for malaria by RDT (Figure 2). RDT-positive individuals were marginally more likely to report any symptoms of malaria in the prior 48 hours and to report multiple symptoms (see Additional file 1). 54.6\% of RDT positive individuals reported a fever in the prior 48 hours but none had a fever on the day of the study visit. RDT positivity was also marginally positively correlated with the presence of anemia.

\section{Discussion}

In this series of cross-sectional studies in southern Zambia, knowledge of the symptoms, causes and prevention of malaria was high in the two study areas over three calendar years. The prevalence of malaria varied over the study period, from $23.9 \%$ in the 2007 study area to $8.1 \%$ and $1.5 \%$ in the 2008 and 2009 study area. Most infected individuals reported symptoms of malaria, although few had documented fever at the time of the study visit. In the first study area, when the prevalence of malaria was highest, several established characteristics were correlated with RDT positivity, including young age, reported symptoms, documented fever, failure to sleep under a bed net, rainy season and use of open water sources. In the second and third study years, with markedly lower malaria prevalence, few individual-level characteristics were correlated with RDT positivity.

Ascertaining and improving general knowledge of malaria is crucial to the acceptance and uptake of prevention practices in a community. The majority of participants in all years correctly identified the symptoms of malaria and knew that malaria was transmitted by mosquitoes. Similar to other regions [18], most participants acquired knowledge of malaria from health workers or at school. However, a considerable proportion of participants either did not report the correct cause of malaria or, as in other studies in the region [19-21], identified other causes primarily related to drinking and eating food. This lack of accurate knowledge regarding causes of malaria was reflected in the level of knowledge regarding preventive measures, particularly in 2007 when ITN distribution began in the area. As few as $40 \%$ of participants reported bed nets as a prevention measure, few other measures were identified, and many participants reported they did not know how to prevent 
Table 3 Use of insecticide treated bed nets, by study years

\begin{tabular}{|c|c|c|c|}
\hline & 2007 & 2008 & 2009 \\
\hline All participants & $N=330$ & $N=435$ & $N=716$ \\
\hline Lives in a households with $\geq 1$ bed net & $135(40.9)$ & $335(77.0)$ & $456(63.7)$ \\
\hline 1 bed net & $92(27.9)$ & $305(70.1)$ & $408(57.0)$ \\
\hline 2 bed nets & $25(7.6)$ & $25(5.8)$ & $37(5.2)$ \\
\hline 3 bed nets & $9(2.7)$ & $5(1.2)$ & $8(1.1)$ \\
\hline$\geq 4$ bed nets & $9(2.7)$ & $0(0.0)$ & $3(0.4)$ \\
\hline Reasons for not owning a bed net & $N=195$ & $N=100$ & $N=260$ \\
\hline Cost & $135(69.2)$ & $72(72.0)$ & $237(91.2)$ \\
\hline Bed nets not available & $44(22.6)$ & $3(3.0)$ & $9(3.5)$ \\
\hline No knowledge of where to buy one & $3(1.5)$ & $7(7.0)$ & $3(1.2)$ \\
\hline Not enough for everyone & $2(1.0)$ & $11(11.0)$ & $0(0.0)$ \\
\hline Not enough space under the bed net & $1(0.5)$ & $0(0.0)$ & $0(0.0)$ \\
\hline No mosquitoes around & $1(0.5)$ & $0(0.0)$ & $2(0.8)$ \\
\hline Frequent changes in sleeping places & $1(0.5)$ & $0(0.0)$ & $4(1.5)$ \\
\hline Too hot under the bed net & $0(0.0)$ & $1(1.0)$ & $0(0.0)$ \\
\hline Belief that bed nets do not protect against mosquitoes & $0(0.0)$ & $1(1.0)$ & $2(0.8)$ \\
\hline Among participants with a bed net & $N=135$ & $N=335$ & $N=456$ \\
\hline Sleeps under the bed net & $61(45.2)$ & $189(56.4)$ & $263(57.7)$ \\
\hline Duration of ownership $<2$ years & $25(41.0)$ & $175(92.6)$ & $207(78.7)$ \\
\hline History of treating bed net & $13(21.3)$ & $49(25.9)$ & $48(18.3)$ \\
\hline Reasons for not sleeping under a bed net & $N=74$ & $N=146$ & $N=193$ \\
\hline No mosquitoes around & $51(68.9)$ & $55(37.7)$ & $89(46.1)$ \\
\hline Inability to hang the bed net/sleeping outside & $3(4.1)$ & $111(76.0)$ & $9(4.7)$ \\
\hline Bed net is old/dirty/needs to be re-treated & $4(5.4)$ & $21(14.4)$ & $25(13.0)$ \\
\hline Frequent changes in sleeping places & $8(10.8)$ & $17(11.6)$ & $18(9.3)$ \\
\hline Too hot under the bed net & $4(5.4)$ & $37(25.3)$ & $29(15.0)$ \\
\hline Not enough space under the bed net & $5(6.8)$ & $0(0.0)$ & $8(4.2)$ \\
\hline Not the rainy season & $1(1.4)$ & $7(4.8)$ & $0(0.0)$ \\
\hline Bed net is itchy & $0(0.0)$ & $5(3.4)$ & $0(0.0)$ \\
\hline Belief that bed nets do not protect against mosquitoes & $0(0.0)$ & $7(4.8)$ & $11(5.7)$ \\
\hline
\end{tabular}

malaria. The survey instrument was based on an allopathic concept of malaria and further ethnographic research is needed to explore the local taxonomy of illness and explanatory models prevalent in the community.

Bed net ownership varied from $40.9 \%$ to $77.0 \%$; however, in all study years, approximately half of participants who owned an ITN did not sleep under it. The primary reason provided for not sleeping under a bed net was the absence of mosquitoes, suggesting seasonal use of ITN. Indeed, participants were more likely to report sleeping under an ITN during the rainy season, as reported in other studies [21]. Other reported reasons for not sleeping under the bed nets were primarily logistical $[19,22]$. These included an inability to hang the bed net or sleeping outside, which was particularly problematic for participants in 2008, changing sleeping places, difficulties sleeping under a bed net due to heat, crowding, or discomfort, and the bed nets being old or dirty. These factors and their impact on ITN use and subsequent protection from malaria infection need to be considered in control programmes to maximize the benefits of ITN.

The prevalence of malaria ranged from $23.9 \%$ in 2007 to $1.5 \%$ in 2009 in this study conducted over three calendar years and two geographical areas. In 2007, when transmission was highest, several well established risk factors correlated with infection, including younger age [23], presence of anaemia [24], using open water sources [4], sleeping without a bed net $[3-5,8]$, rainy season $[5,7]$, and self-reported or documented symptoms [2]. However, in 2008 and 2009, when the prevalence of malaria was substantially lower, only self-reported or documented fever correlated with infection. With 


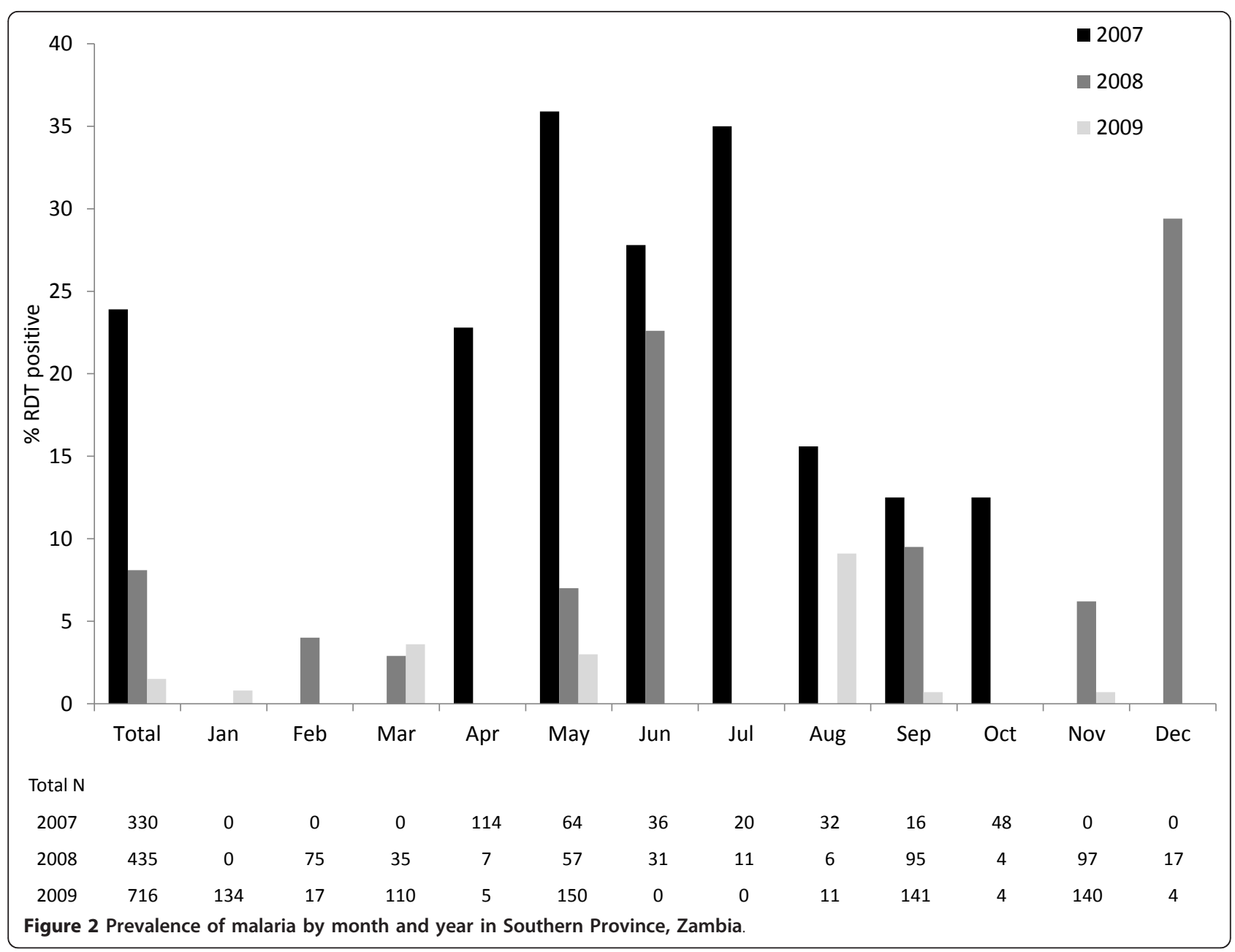

declining prevalence, malaria was no longer likely to be diagnosed in the rainy season or among individuals sleeping without a bed net. The median age of infected individuals increased from 9.0 years with high parasite prevalence to 12.5 and 13.2 years with low prevalence, and was no longer significantly different from the age of the general study population. This shift to higher age groups with declining transmission has been observed in other studies and settings $[8,23,25]$. Although the power to detect differences decreased with declining malaria prevalence, many characteristics correlated with RDT positivity in 2007 were not associated with RDT positivity in 2008 and 2009.

Only symptoms, particularly fever, correlated with RDT positivity in the time periods with low levels of parasite prevalence. When all symptoms of malaria were considered together, infected individuals were more likely to report symptoms and in greater numbers in 2007 and again in 2009. However, in all years, symptoms of malaria were highly prevalent in RDT-negative individuals, with up to $63 \%$ of RDT-negative individuals reporting symptoms within the 48 hours prior to the

Table 4 Prevalence ratios for correlates of RDT positivity among participants in 2007

\begin{tabular}{lcc}
\hline Characteristic & Crude prevalence ratio $\mathbf{9 5 \%} \mathbf{C l})$ & Adjusted prevalence ratio (95\% Cl) \\
\hline Age in years & $0.98(0.97,0.99)$ & $0.98(0.97,0.99)$ \\
\hline Any symptoms in prior 48 hours & $1.94(1.29,2.93)$ & $2.06(1.33,3.17)$ \\
\hline Sleeps under a bed net & $0.50(0.24,1.03)$ & $0.50(0.25,1.02)$ \\
\hline Rainy season & $1.60(0.85,2.99)$ & $1.67(1.00,2.80)$ \\
\hline Presence of anaemia & $1.45(1.02,2.06)$ & $1.27(0.92,1.75)$ \\
\hline Open water source & $1.72(1.04,2.85)$ & $1.74(1.14,2.64)$ \\
\hline
\end{tabular}


study visit, thus decreasing the specificity of symptoms in identifying infected persons. RDT-positive individuals were more likely to have documented fever in 2007 and 2008 but only $10-20 \%$ of positive individuals had fever. Most RDT-positive individuals were without fever at the time of testing. Other studies in various transmission settings found a large proportion (up to 96\%) of individuals infected with malaria to be asymptomatic [26-28]. This finding poses a significant challenge to malaria elimination as many control strategies rely on the identification and treatment of symptomatic individuals seeking care at health centres [29].

This study was subject to several limitations. First, the study was conducted over two geographic areas. Participants surveyed in 2008 and 2009 were from the same geographic area, while those surveyed in 2007 were from an area further east. Consequently, it is possible that the different risk factors found between the two areas, was not due to the decline in malaria transmission but to differences in the ecology or characteristics and behaviours of the participants surveyed. When participants and households were compared, however, there did not appear to be many differences based on measured characteristics. Second, we did not collect information on behaviors, occupation, assets, migration, and travel that might be associated with malaria. Finally, as previously discussed, the power to detect associations was low in 2008 and 2009 with declining malaria transmission.

\section{Conclusions}

In an area with high malaria prevalence, several established, individual-level characteristics were correlated with RDT positivity. With lower malaria prevalence, however, few individual-level characteristics were correlated with RDT positivity and the majority of infected persons were asymptomatic. This lack of correlation with previously established individual-level characteristics hampers identification of asymptomatic-infected individuals critical to the development of a malaria elimination programme in Zambia [13]. Strategies based on ecological or environmental risk factors [30] may be needed to target control efforts and achieve further reductions and elimination in southern Zambia.

\section{Additional material}

Additional file 1: Correlates of RDT positivity, by study year. ${ }^{a}$ among participants 18 years of age or older ${ }^{b}$ self-reported symptoms include fever, headache, chills, nausea/vomiting, cough, diarrhea anemia defined by age and sex: $<11 \mathrm{~g} / \mathrm{dL}$ for children 0-4.9 yrs; $<11.5$ $\mathrm{g} / \mathrm{dL}$ for children 5-11.9 yrs; $<12 \mathrm{~g} / \mathrm{dL}$ for children $12-14.9 \mathrm{yrs} ;<12 \mathrm{~g} / \mathrm{dL}$ for women $\geq 15 \mathrm{yrs} ;<13 \mathrm{~g} / \mathrm{dL}$ for men $\geq 15 \mathrm{yrs}{ }^{\mathrm{d}}$ open water source: unprotected well or river/stream.

\section{List of abbreviations}

EIR: entomological inoculation rate; IQR: inter-quartile range; ITN: insecticidetreated net; RDT: rapid diagnostic test.

\section{Acknowledgements}

This work was supported by the Johns Hopkins Malaria Research Institute and the Bloomberg Family Foundation.

\section{Author details}

${ }^{1}$ Department of Epidemiology, Bloomberg School of Public Health, Johns Hopkins University, 615 North Wolfe Street, Baltimore, MD, USA. ${ }^{2}$ W. Harry Feinstone Department of Molecular Microbiology and Immunology, Bloomberg School of Public Health, Johns Hopkins University, 615 North Wolfe Street, Baltimore, MD, USA. ${ }^{3}$ Malaria Research Trust, Choma, Zambia.

\section{Authors' contributions}

CGS performed the data analysis and drafted the manuscript. TK participated in the coordination of the study and reviewed the manuscript. $\mathrm{HH}$ participated in the design and coordination of field aspects of the study and reviewed the manuscript. TS participated in the design and coordination of the study and reviewed the manuscript. AK participated in the design and coordination of field aspects of the study and reviewed the manuscript. SM participated in the design and coordination of the study and reviewed the manuscript. PET participated in the design and coordination of the study and reviewed the manuscript. GG participated in the design and coordination of the study and reviewed the manuscript. WJM conceived of the study, participated in its design and coordination, and participated in the preparation of the manuscript. All authors read and approved the final manuscript.

\section{Competing interests}

The authors declare that they have no competing interests.

Received: 4 August 2011 Accepted: 31 October 2011

Published: 31 October 2011

\section{References}

1. WHO: World malaria report 2010 Geneva, Switzerland: World Health Organization; 2010.

2. Stich A, Oster N, Abdel-Aziz IZ, Stieglbauer G, Coulibaly B, Wickert H, McLean J, Kouyate BA, Becher H, Lanzer M: Malaria in a holoendemic area of Burkina Faso: a cross-sectional study. Parasitol Res 2006, 98:596-599.

3. Clark TD, Greenhouse B, Njama-Meya D, Nzarubara B, Maiteki-Sebuguzi C, Staedke SG, Seto E, Kamya MR, Rosenthal PJ, Dorsey G: Factors determining the heterogeneity of malaria incidence in children in Kampala, Uganda. J Infect Dis 2008, 198:393-400.

4. Njama D, Dorsey G, Guwatudde D, Kigonya K, Greenhouse B, Musisi S, Kamya MR: Urban malaria: primary caregivers' knowledge, attitudes, practices and predictors of malaria incidence in a cohort of Ugandan children. Trop Med Int Health 2003, 8:685-692.

5. Baragatti M, Fournet F, Henry MC, Assi S, Ouedraogo H, Rogier C, Salem G: Social and environmental malaria risk factors in urban areas of Ouagadougou, Burkina Faso. Malar J 2009, 8:13.

6. Brentlinger PE, Montoya P, Rojas AJ, Correia MA, Dgedge M, Saute F, Gimbel-Sherr K, Mercer MA, Gloyd S: Prevalence and predictors of maternal peripheral malaria parasitemia in central Mozambique. Am J Trop Med Hyg 2007, 77:228-234.

7. Rogerson SJ, van den Broek NR, Chaluluka E, Qongwane C, Mhango CG, Molyneux ME: Malaria and anemia in antenatal women in Blantyre, Malawi: a twelve-month survey. Am J Trop Med Hyg 2000, 62:335-340.

8. Winskill P, Rowland M, Mtove G, Malima RC, Kirby MJ: Malaria risk factors in north-east Tanzania. Malar J 2011, 10:98.

9. Chizema-Kawesha E, Miller JM, Steketee RW, Mukonka VM, Mukuka C, Mohamed AD, Miti SK, Campbell CC: Scaling up malaria control in Zambia: progress and impact 2005-2008. Am J Trop Med Hyg 2010, 83:480-488.

10. Riedel N, Vounatsou P, Miller JM, Gosoniu L, Chizema-Kawesha E, Mukonka V, Steketee RW: Geographical patterns and predictors of malaria risk in Zambia: Bayesian geostatistical modelling of the 2006 Zambia national malaria indicator survey (ZMIS). Malar J 2010, 9:37. 
11. Mharakurwa S, Thuma PE, Norris DE, Mulenga M, Chalwe V, Chipeta J, Munyati S, Mutambu S, Mason PR: Malaria epidemiology and control in Southern Africa. Acta Trop 2011.

12. Moss WJ, Norris DE, Mharakurwa S, Scott A, Mulenga M, Mason PR, Chipeta J, Thuma PE: Challenges and prospects for malaria elimination in the Southern Africa region. Acta Trop 2011.

13. WHO: Roll Back Malaria. Focus on Zambia. Progress and Impact Series Country Report No 2 Geneva, Switzerland: World Health Organization; 2011.

14. Kent RJ, Thuma PE, Mharakurwa S, Norris DE: Seasonality, blood feeding behavior, and transmission of Plasmodium falciparum by Anopheles arabiensis after an extended drought in southern Zambia. Am J Trop Med Hyg 2007, 76:267-274.

15. Larkin GL, Thuma PE: Congenital malaria in a hyperendemic area. Am J Trop Med Hyg 1991, 45:587-592.

16. WHO: Malaria rapid diagnostic test performance: results of WHO product testing of malaria RDTs: round 1 (2008) France: World Health Organization; 2009.

17. WHO: Iron deficiency anaemia: Assessment, prevention and control: A guide for programme managers Geneva, Switzerland: World Health Organization; 2001.

18. Hongwana KW, Mabaso ML, Kunene S, Govender D, Maharaj R: Community knowledge, attitudes and practices (KAP) on malaria in Swaziland: a country earmarked for malaria elimination. Malar J 2009, $8: 29$.

19. Ng'ang'a PN, Jayasinghe G, Kimani V, Shililu J, Kabutha C, Kabuage L, Githure J, Mutero C: Bed net use and associated factors in a rice farming community in Central Kenya. Malar J 2009, 8:64.

20. Dye TD, Apondi R, Lugada ES, Kahn JG, Smith J, Othoro C: "Before we used to get sick all the time": perceptions of malaria and use of long-lasting insecticide-treated bed nets (LLINs) in a rural Kenyan community. Malar J 2010, 9:345.

21. Okrah J, Traore C, Pale A, Sommerfeld J, Muller O: Community factors associated with malaria prevention by mosquito nets: an exploratory study in rural Burkina Faso. Trop Med Int Health 2002, 7:240-248.

22. Alaii JA, van den Borne HW, Kachur SP, Mwenesi H, Vulule JM, Hawley WA, Meltzer Ml, Nahlen BL, Phillips-Howard PA: Perceptions of bed nets and malaria prevention before and after a randomized controlled trial of permethrin-treated bed nets in western Kenya. Am J Trop Med Hyg 2003, 68:142-148.

23. Carneiro I, Roca-Feltrer A, Griffin JT, Smith L, Tanner M, Schellenberg JA, Greenwood B, Schellenberg D: Age-patterns of malaria vary with severity, transmission intensity and seasonality in sub-Saharan Africa: a systematic review and pooled analysis. PLoS One 2010, 5:e8988.

24. Maina RN, Walsh D, Gaddy C, Hongo G, Waitumbi J, Otieno L, Jones D, Ogutu BR: Impact of Plasmodium falciparum infection on haematological parameters in children living in Western Kenya. Malar J 2010, 9(Suppl 3): S4.

25. Okiro EA, Al-Taiar A, Reyburn H, Idro R, Berkley JA, Snow RW: Age patterns of severe paediatric malaria and their relationship to Plasmodium falciparum transmission intensity. Malar J 2009, 8:4.

26. Mabunda S, Aponte JJ, Tiago A, Alonso P: A country-wide malaria survey in Mozambique. II. Malaria attributable proportion of fever and establishment of malaria case definition in children across different epidemiological settings. Malar J 2009, 8:74.

27. Harris I, Sharrock WW, Bain LM, Gray KA, Bobogare A, Boaz L, Lilley K, Krause D, Vallely A, Johnson ML, Gatton ML, Shanks GD, Cheng Q: A large proportion of asymptomatic Plasmodium infections with low and submicroscopic parasite densities in the low transmission setting of Temotu Province, Solomon Islands: challenges for malaria diagnostics in an elimination setting. Malar J 2010, 9:254

28. Owusu-Agyei S, Smith T, Beck HP, Amenga-Etego L, Felger I: Molecular epidemiology of Plasmodium falciparum infections among asymptomatic inhabitants of a holoendemic malarious area in northern Ghana. Trop Med Int Health 2002, 7:421-428.

29. Moonen B, Cohen JM, Snow RW, Slutsker L, Drakeley C, Smith DL, Abeyasinghe RR, Rodriguez MH, Maharaj R, Tanner M, Targett G: Operational strategies to achieve and maintain malaria elimination. Lancet 2010, 376:1592-1603.

30. Moss WJ, Hamapumbu H, Kobayashi T, Shields T, Kamanga A, Clennon J, Mharakurwa S, Thuma PE, Glass G: Use of remote sensing to identify spatial risk factors for malaria in a region of declining transmission: a cross-sectional and longitudinal community survey. Malar J 2011, 10:163.

doi:10.1186/1475-2875-10-324

Cite this article as: Sutcliffe et al.: Changing individual-level risk factors for malaria with declining transmission in southern Zambia: a crosssectional study. Malaria Journal 2011 10:324.

\section{Submit your next manuscript to BioMed Central and take full advantage of:}

- Convenient online submission

- Thorough peer review

- No space constraints or color figure charges

- Immediate publication on acceptance

- Inclusion in PubMed, CAS, Scopus and Google Scholar

- Research which is freely available for redistribution

Submit your manuscript at www.biomedcentral.com/submit
Biomed Central 